\title{
The cAMP-Dependent Protein Kinase Regulates Transcription of the Dopamine $\beta$-Hydroxylase Gene
}

\author{
Kwang-Soo Kim, ${ }^{1}$ Hiroshi Ishiguro,, ${ }^{1}$ Cristina Tinti,, John Wagner, ${ }^{2}$ and Tong H. Joh' \\ 'Laboratory of Molecular Neurobiology, Department of Neurology and Neuroscience, Cornell University Medical College at \\ The W. M. Burke Medical Research Institute, White Plains, New York 10605, and 2Department of Neurology and \\ Neuroscience and Department of Cell Biology and Anatomy, Cornell University Medical College, New York, New York \\ 10021
}

Dopamine $\beta$-hydroxylase (DBH) catalyzes the conversion of dopamine to norepinephrine, and is expressed specifically in neurons and neuroendocrine cells that release norepinephrine and epinephrine. In the present study, we used DBH-expressing human neuroblastoma SK-N-BE(2)C and rat pheochromocytoma (PC12) cell lines to investigate the role of CAMP-dependent protein kinase (PKA) in transcriptional regulation of the DBH gene. Coexpression of the catalytic subunit of PKA (PKA $)$ robustly stimulated the transcriptional activity of the DBH gene in a dose-dependent manner. Conversely, coexpression of a specific inhibitor of PKA abrogated forskolin- and CAMP-mediated but not phorbol estermediated transcriptional induction of DBH. Deletion of the CAMP response element (CRE) dramatically reduced the stimulatory effect of PKA, indicating that the CRE mediates the induction of DBH by PKA. In DBH-nonexpressing HeLa and $\mathbf{C 6}$ glioma cell lines, coexpression of PKA $\mathrm{A}_{\mathrm{c}}$ changed the transcriptional activity of the DBH promoter to a minimal degree, indicating that basal and PKA-mediated transcription of the DBH gene occur in a cell type-specific manner. Finally, both basal and CAMP-stimulated transcription of the DBH gene are diminished in three PKA-deficient PC12 cell lines, compared to wild-type cells. Based on these data, we conclude that PKA, via the CRE, plays an important role in basal and cAMP-inducible transcription, but is not required for phorbol ester-mediated induction, of the DBH gene in noradrenergic cells. The present results, together with previous evidence supporting a critical role for PKA in the transcriptional regulation of the tyrosine hydroxylase (TH) gene, suggest that the PKA pathway can regulate transcription of the TH and DBH genes in a coordinated fashion.

[Key words: cAMP, cAMP-dependent protein kinase (PKA), dopamine $\beta$-hydroxylase, transcriptional regulation, tyrosine hydroxylase, norepinephrine biosynthesis, cAMP response element, polypeptide inhibitor of PKA (PKI), primer extension, cotransfection analysis]

Received Mar. 14, 1994; revised May 23, 1994; accepted May 26, 1994.

This work was supported by NIH Grants MH48866 (to K.-S.K.) and MH24285 (to T.H.J.) We are grateful to Dr. R. Maureer (University of Iowa) for the generous gifts of RSV-PKI and RSV-PKIm plasmids. We thank to Drs. Joseph Cubells, Maria Febbraio, and Harriet Baker in our laboratory for critical reading of the manuscript and Bai Song for his excellent technical assistance.

Correspondence should be addressed to K.-S. Kim, Laboratory of Molecular Neurobiology, Department of Neurology and Neuroscience, Cornell University Medical College at The W. M. Burke Medical Research Institute, 785 Mamaroneck Avenue, White Plains, NY 10605.

Copyright (C) 1994 Society for Neuroscience $0270-6474 / 94 / 147200-08 \$ 05.00 / 0$
The catecholamines, that is, dopamine, norepinephrine, and epinephrine, are differentially synthesized in subsets of catecholamine neurons and neuroendocrine cells in a cell-specific manner. Underlying this specificity of synthesis is cell-specific expression of the enzymes catalyzing catecholamine biosynthesis. For example, dopamine $\beta$-hydroxylase (DBH; EC 1.14.17.1) converts dopamine to norepinephrine (Kirshner and Goodall, 1957; Friedman and Kaufman, 1965). Its expression thus confers a noradrenergic or adrenergic phenotype on catecholaminesynthesizing cells. At present, the molecular mechanisms underlying tissue-specific expression of catecholamines and their biosynthesizing enzymes are not well understood.

Norepinephrine- and epinephrine-secreting cells regulate the level of tyrosine hydroxylase (TH) and $\mathrm{DBH}$ gene expression in response to a variety of transsynaptic, hormonal, and growth factor signals, including cAMP analogs (Sabban et al., 1983; Lewis et al., 1987; Lamouroux et al., 1993), nerve growth factor (Acheson et al., 1984; Badoyannis et al., 1991), glucocorticoids (Otten and Thoenen, 1976; K. T. Kim et al., 1993), reserpine (Faucon Biguet et al., 1986; Wessel and Joh, 1993), and immobilization stress (McMahon et al., 1992). TH and DBH expression change in the same direction in response to such stimuli, suggesting that common regulatory mechanisms influence transcription of the genes encoding these enzymes. Several lines of evidence from this laboratory support the hypothesis that TH and DBH share common molecular mechanisms of transcriptional control. For example, the cAMP response element (CRE) plays an important dual role in both basal and CAMPstimulated transcription of the TH gene (K. S. Kim et al., 1993a). Similarly, the CRE is an essential positive genetic element for cell-specific and forskolin-stimulated expression of the human DBH gene (Ishiguro et al., 1993).

Recent data from this laboratory demonstrated that the PKAsignaling pathway regulates both the basal and cAMP-inducible transcription of the TH gene (K. S. Kim et al., 1993b, 1994). These observations prompted us to hypothesize that PKA also controls basal and cAMP-inducible transcription of the DBH gene, resulting in a coordinated regulation of the TH and DBH genes by PKA. The present study examined this possibility by transient transfection assays using reporter constructs containing 5 ' flanking sequences of the human DBH gene fused to the bacterial chloramphenicol acetyltransferase (CAT) gene. We tested the effects of coexpression of the catalytic subunit of PKA, or a specific peptide inhibitor of PKA, on the transcriptional activity of these reporter constructs in the human neuroblastoma SK-N-BE(2)C (DBH-expressing) and HeLa (DBH-nonex- 
pressing) cell lines. In addition, we analyzed basal and cAMPstimulated induction of $\mathrm{DBH}$ gene transcription in several PKA-deficient mutant PC12 lines. This study strongly suggests that PKA, acting via the CRE, plays a key role in the transcriptional regulation of the DBH gene in noradrenergic cells. These findings support the hypothesis that the PKA pathway functions as a common regulatory mechanism for DBH and TH gene transcription.

\section{Materials and Methods}

Cell culture and treatment with effector molecules. Human neuroblastoma cell lines SK-N-BE(2)C and SK-N-BE(2)M17, which express both tyrosine hydroxylase and dopamine $\beta$-hydroxylase (Ciccarone et al., 1989; Carroll et at., 1991; Ishiguro et al., 1993), and HeLa and C6 glioma cells, which do not express either enzyme, were maintained as described before (Ishiguro et al., 1993; K. S. Kim et al., 1993a). After $30-40$ passages, cell cultures were restarted from early passage cells stored in liquid nitrogen. Stock solutions $(1000 \times)$ of forskolin and the phorbol ester tetradecanoyl phorbol acetate (TPA) were prepared in dimethyl sulfoxide and added directly to the culture medium 16-18 hr before cells were harvested, to achieve final concentrations of $10 \mu \mathrm{M}$ and $0.1 \mu \mathrm{g} / \mathrm{ml}$, respectively. To inhibit phosphodiesterase activity, forskolin treatment was always paired with 3-isobutyryl-1-methylxanthine (IMX) to a final concentration of $0.5 \mathrm{~mm}$. The intracellular activity of PKA was determined according to the published procedure (Roskoski, 1983), using the assay kit (GIBCO-Bethesda Research Labs). Mutant PC1 2 cell lines were rendered PKA deficient either by genetic manipulation (Ginty et al., 1991a; AB.11 and 123.7 cell lines) or chemical mutagenesis (Buskirk et al., 1985; A126-1B2 cell line). These mutant and wild-type PC12 cells were maintained and grown as described (K. S. Kim et al., 1993b).

Plasmids. The DBH-CAT reporter constructs 2.6CAT, 978CAT, and $\triangle C R E$ 978CAT were described previously (Fig. 1; Ishiguro et al., 1993). 2.6CAT contains the intact $2.6 \mathrm{~kb}$ upstream sequence of the human DBH gene fused to the chloramphenicol acetyl transferase gene. $\triangle \mathrm{CRE}$ 978CAT contains 978 bp of the upstream sequence, in which 14 bases $(-189$ to -176$)$, encompassing the CRE, were deleted. The heat-stable specific inhibitor of PKA (PKI) and its mutant form (PKI $\left.{ }^{\mathrm{m}}\right)$ were expressed using plasmids RSV-PKI and RSV-PKIm (Day et al., 1989), generously provided by Dr. R. Maureer (University of Iowa). These plasmids utilize the promoter/enhancer region of the Rous sarcoma virus to direct expression of PKI. The expression plasmid for the cat-

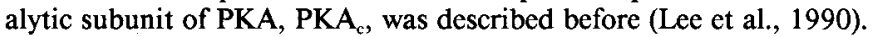

Transient transfection experiments. Transient transfection of the DBHCAT reporter construct and effector molecules of PKA were performed by the calcium phosphate coprecipitation method as described before (Ishiguro et al., 1993; K. S. Kim et al., 1993a). When SK-N-BE(2)C or SK-N-BE(2)M 17 cells reached approximately $50 \%$ confluence, each 60 $\mathrm{mm}$ dish was transfected with $2 \mu \mathrm{g}$ of the reporter construct, varying amounts of the effector expression plasmid, $1 \mu \mathrm{g}$ of pRSV- $\beta$ gal, and PUC1 9 plasmid to a total DNA concentration of $5 \mu \mathrm{g}$. For HeLa and C6 glioma cells, twice as much DNA was used in transfection. To correct for differences in transfection efficiency among different DNA precipitates, CAT activity was normalized to the activity of $\beta$-galactosidase. The experiments described in Figure 3 utilized $2 \mu \mathrm{g}$ of SV $40-\beta$ gal for normalization. Assays of chloramphenicol acetyltransferase and $\beta$-galactosidase were performed as described (Ishiguro et al., 1993; K. S. Kim et al., 1993a).

Northern blot hybridization. To analyze the steady-state levels of mRNA of wild-type and mutant $\mathrm{PC} 12$ cells, polyA ${ }^{+}$RNA was isolated by oligo(dT)-cellulose affinity column chromatography (Badley et al., 1988). A cDNA probe for the rat DBH gene, isolated in this laboratory $(K . T$. Kim et al., 1993), was used to identify the DBH message. Northern hybridization experiments were performed using $2 \mu \mathrm{g}$ of polyA + RNA per lane as described (K. S. Kim et al., 1993b). Levels of mRNA were quantitated and compared using a PhosphorImager and IMAGEQuANT software (Molecular Dynamics) and were normalized to those of a control gene, $\alpha$-tubulin.

Primer extension analysis of fusion gene transcripts. To analyze the RNA products of the transient expression assays, a total of $15 \mu \mathrm{g}$ of DNA containing $9 \mu \mathrm{g}$ of the 2.6CAT plasmid and varying amounts of $\mathrm{PKA}_{\mathrm{c}}$ was coprecipitated and transfected into cells grown to approximately $50 \%$ confluence in a $100 \mathrm{~mm}$ dish. The transcription initiation
DBH-CAT reporter constructs

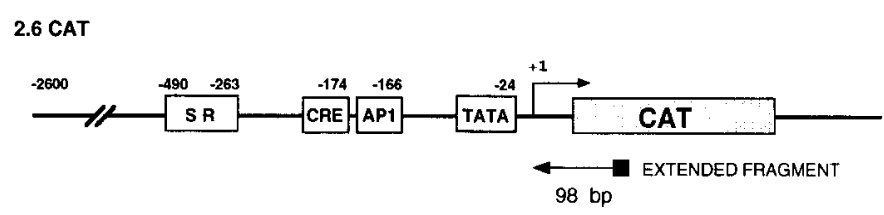

moar

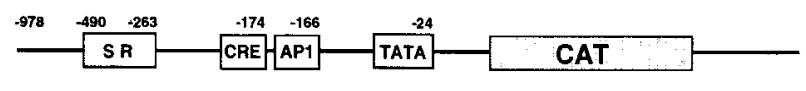

$\triangle$ CRE 978CAT

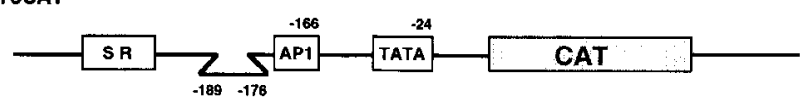

Figure 1. A schematic diagram of the DBH-CAT reporter constructs. $2.6 C A T$ and $978 C A T$ contain $2.6 \mathrm{~kb}$ and $978 \mathrm{bp}$ of the $5^{\prime}$ flanking sequence of the human DBH gene, respectively. Both sequences are capable of cell-specific transcription in cell culture systems (Ishiguro et al., 1993). $\triangle C R E$ 978CAT is identical to $978 \mathrm{CAT}$, except $14 \mathrm{bp}(-189$ to -176), encompassing the CRE, has been deleted. Sequence motifs of the human DBH gene, previously identified and/or characterized (Kobayashi et al., 1989; Ishiguro et al., 1993; Lamouroux et al., 1993) and their relative position are represented by numbered white boxes. $S R$ denotes the silencer region necessary for cell specificity of the DBH gene (Ishiguro et al., 1993). +1 and the bent arrow denote the transcription initiation (CAP) site. The black box represents the oligonucleotide used in the primer extension and sequencing reactions.

site of the reporter gene was determined by primer extension analysis as described (McKnight and Kingsbury, 1982), with the following modifications: polyA ${ }^{+}$mRNA was isolated from SK-N-BE(2)C cells $36 \mathrm{hr}$ after transfection as described above for the Northern hybridization experiments. An oligonucleotide (5'-CGGTGGTATATCCAGTG-3') complementary to nucleotides 15-31 of the coding sequence of the CAT gene was end labeled by T4 polynucleotide kinase (NEB) using $\gamma-{ }^{32} \mathrm{P}$ ATP (6000 Ci mmol-1; Amersham). Approximately $0.05 \mathrm{ng}$ of labeled primer (specific activity, $2 \times 10^{9} \mathrm{cpm} / \mu \mathrm{g}$ ) was mixed with $4 \mu \mathrm{g}$ of polyA $\mathrm{A}^{+}$ RNA. Annealed primer was extended by 100 units of MMLV-reverse transcriptase (Bethesda Research Labs-GIBCO) at $37^{\circ} \mathrm{C}$ for $2 \mathrm{hr}$, in the presence of RNase inhibitor (U.S. Biochemical) and four deoxynucleotides. After RNase treatment, phenol/chloroform extraction, and EtOH precipitation, the final reaction mix was resuspended in $10 \mu \mathrm{l}$ of loading gel buffer. Four microliters of each extension product were analyzed on an $8 \%$ polyacrylamide sequencing gel. A parallel dideoxy sequencing reaction was performed, utilizing the same oligonucleotide primer described above. An $\mathrm{m} 13 \mathrm{mp} 19$ subclone containing the $1.3 \mathrm{~kb}$ SphI-EcoRI fragment from 978CAT plasmid (Ishiguro et al., 1993) served as the template. The gel was fixed, vacuum dried, exposed at $-70^{\circ} \mathrm{C}$ for $36 \mathrm{hr}$ with an intensifying screen, and visualized by autoradiography.

\section{Results}

Expression of the catalytic subunit of PKA stimulates the transcriptional activity of the human DBH gene promoter in a cell type-specific manner

To define the role of PKA in transcriptional regulation of the DBH gene, three DBH-CAT fusion constructs were employed in this study as reporter plasmids. The 2.6CAT and 978CAT plasmids contain the intact 2600 bp and 978 bp upstream sequences of the human DBH gene, respectively. The $\triangle \mathrm{CRE}$ 978CAT plasmid contains 978 bp of upstream sequence, with the deletion of $14 \mathrm{bp}(-189$ to -176$)$ encompassing the CRE (Fig. 1). To analyze the role of PKA in transcriptional regulation of the DBH gene, an expression plasmid encoding PKA $_{c}$ was cotransfected with the DBH-CAT fusion constructs into human 


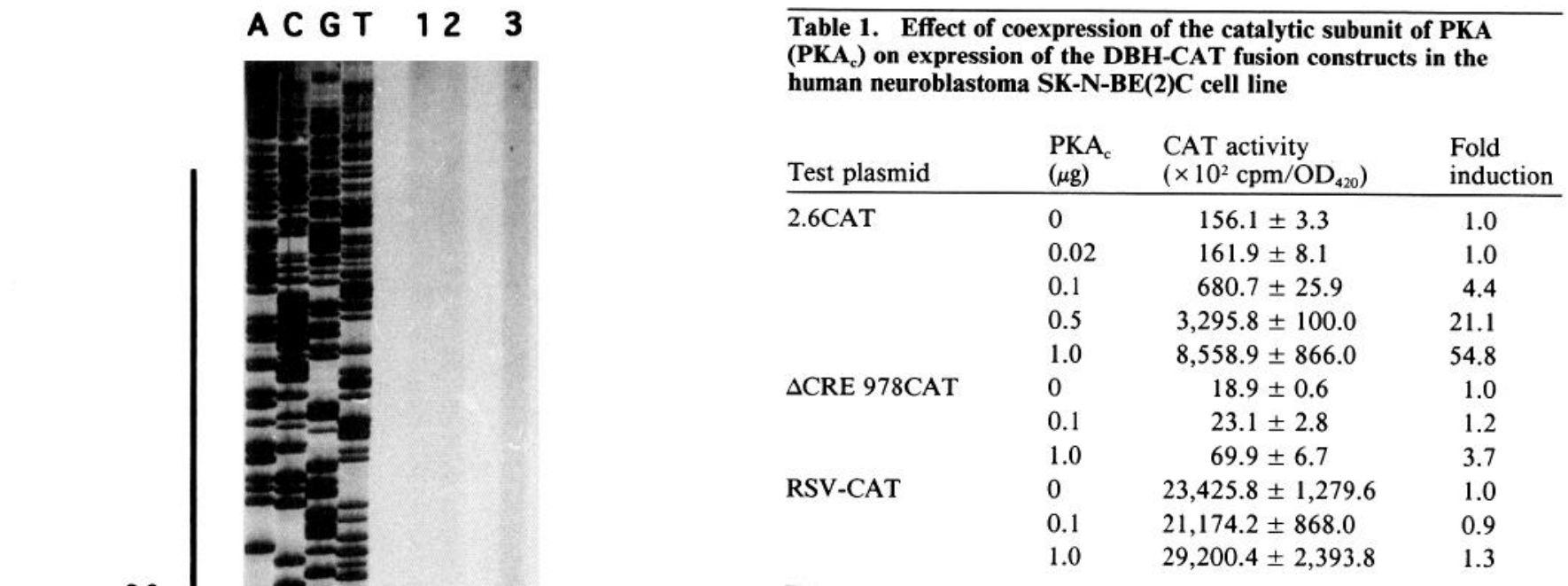

TATA -24
+1
7
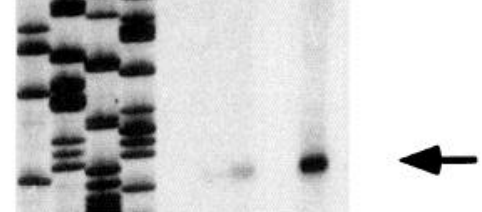
CAT reporter constructs as indicated. The CAT activity was assayed after determination of the appropriate dilution such that the activity would be within the linear range. To correct for differences in transfection efficiency, CAT activity was normalized to the activity of $\beta$-galactosidase, and presented as mean value \pm SEM from triplicate samples. This experiment was repeated twice more in triplicate using independently prepared plasmid DNAs, and resulted in similar patterns.

neuroblastoma SK-N-BE(2)C and SK-N-BE(2)M17 cells, and the effect on the transcriptional activity of the reporter constructs was assessed by measuring CAT activities. $\mathrm{PKA}_{\mathrm{c}}$ robustly induces expression of 2.6CAT as much as 50 -fold in a dosedependent manner (Table 1). This clearly demonstrates that $\mathrm{PKA}_{\mathrm{c}}$ can induce promoter activity of the upstream sequence of the DBH gene. The induction of transcriptional activity of the DBH upstream sequence is promoter specific, since the promoter/enhancer of the Rous Sarcoma virus is virtually nonresponsive to $\mathrm{PKA}_{\mathrm{c}}$ (Table 1). When the CRE-deleted reporter construct, $\triangle \mathrm{CRE}$ 978CAT, was used, not only was basal expression much diminished (approximately $90 \%$ ), but the $\mathrm{PKA}_{\mathrm{c}}$ mediated stimulatory effect was also significantly inhibited (Table 1). In contrast, $978 \mathrm{CAT}$, containing the intact $\mathrm{CRE}$, exhibited the same responsiveness to $\mathrm{PKA}_{\mathrm{c}}$ as 2.6CAT (data not shown), implying that the CRE is the primary target site for the action of PKA. Primer extension analysis using a primer against coding sequences of CAT from these studies showed that levels of correctly initiated CAT transcripts of the predicted fragment length of $98 \mathrm{bp}$ (Kobayashi et al., 1989), rose in parallel with the robust induction of CAT activity by PKA (Fig. 2). This demonstrates that the $\mathrm{PKA}_{\mathrm{c}}$-induced increase of $\mathrm{DBH}$ promoter activity represents a genuine transcriptional event. To determine whether this robust induction of DBH transcriptional activity by $\mathrm{PKA}_{\mathrm{c}}$ is a general phenomenon or occurs only in a specific cellular context, we performed the same coexpression analysis in DBH-nonexpressing HeLa cell line (Table 2). Strikingly, even the maximum amount of $\mathrm{PKA}_{\mathrm{c}}$ did not alter the transcriptional activity of the DBH upstream sequence. Thus, in the DBH-negative HeLa cell line, not only the basal expression of the DBH-CAT fusion construct (Ishiguro et al., 1993), but also its inducibility in response to $\mathrm{PKA}_{\mathrm{c}}$ activation are defective. We also examined PKA-inducible transcription of the

Figure 2. Primer extension analysis of RNA transcripts produced by the DBH-CAT fusion construct in the absence or presence of increasing amounts of $\mathrm{PKA}_{\mathrm{c}} . A, C, G$, and $T$, dideoxy sequence ladders of the upstream and junction areas of the DBH-CAT fusion gene with the same oligonucleotide used in primer extension analysis. Lane 1, primer extension of RNA isolates from SK-N-BE(2)C transfected with 2.6CAT only; lanes 2 and 3, RNA isolated from SK-N-BE(2)C cells cotransfected with 2.6CAT and $\mathrm{PKA}_{\mathrm{c}}(0.3 \mu \mathrm{g}$, lane $2 ; 1.5 \mu \mathrm{g}$, lane 3). The bent arrow, at +1 , denotes the transcription start site. The primer-extended product and free primers are indicated by thin and thick arrows to the right, respectively. Robust, dose-dependent increase of the correctly initiated transcript of the DBH-CAT fusion gene is demonstrated. 


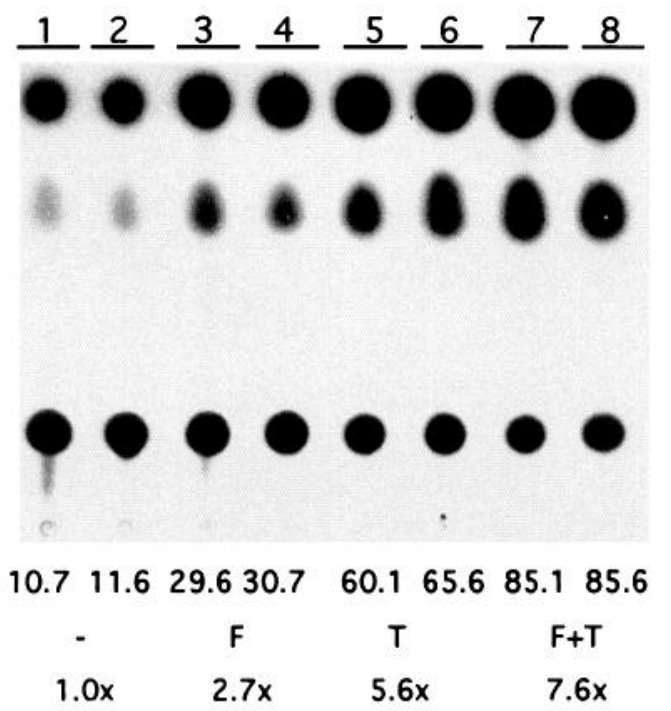

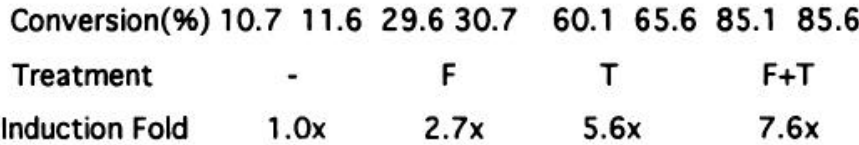

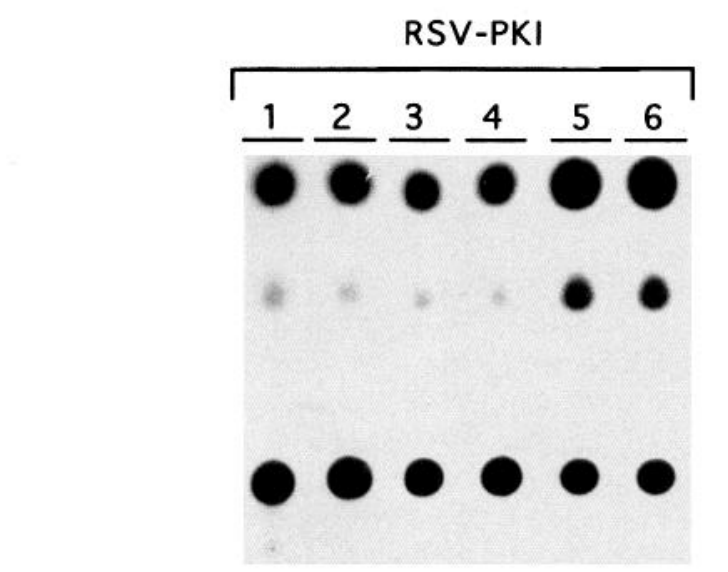

Conversion(\%) $10.911 .7 \quad 13.7 \quad 14.9 \quad 59.5 \quad 59.5$

$\begin{array}{cccc}\text { Treatment } & - & \mathrm{F} & \mathrm{T} \\ \text { Induction Fold } & 1.0 \mathrm{x} & 1.3 \mathrm{x} & 5.3 \mathrm{x}\end{array}$

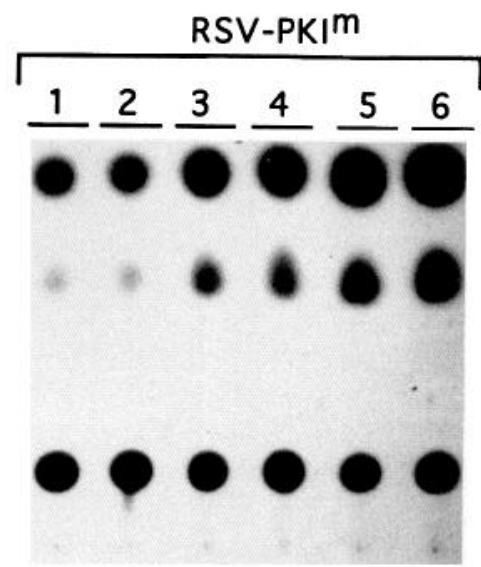

Conversion(\%) $12.1 \quad 12.4 \quad 36.6 \quad 34.3 \quad 70.5 \quad 73.2$

Treatment

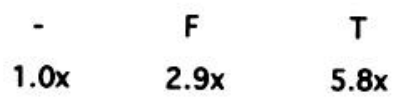

Table 2. Coexpression of the catalytic subunit of PKA (PKA) induces the CAT activity of the DBH-CAT fusion construct (2.6CAT) to a minimal degree in HeLa and $\mathrm{C} 6$ glioma cells

\begin{tabular}{llll} 
Cell line & $\begin{array}{l}\mathrm{PKA}_{\mathrm{c}} \\
(\mu \mathrm{g})\end{array}$ & $\begin{array}{l}\text { CAT activity } \\
\left(\times 10^{2} \mathrm{cpm} / \mathrm{OD}_{420}\right)\end{array}$ & $\begin{array}{l}\text { Fold } \\
\text { induc- } \\
\text { tion }\end{array}$ \\
\hline HeLa & 0 & $52.5 \pm 0.9$ & 1.0 \\
& 0.1 & $52.8 \pm 1.8$ & 1.0 \\
& 0.5 & $58.5 \pm 3.1$ & 1.1 \\
C6 glioma & 1.0 & $69.9 \pm 6.9$ & 1.3 \\
& 0 & $80.3 \pm 3.8$ & 1.0 \\
& 0.1 & $81.6 \pm 8.3$ & 1.0 \\
& 0.5 & $183.2 \pm 25.1$ & 2.3 \\
& 1.0 & $193.4 \pm 20.5$ & 2.4 \\
\hline
\end{tabular}

Cotransfection was performed using increasing amount of $\mathrm{PKA}_{\mathrm{c}}$ as described in Materials and Methods. CAT activities are presented as in Table 1. The CAT activity of RSV-CAT was also not affected by cotransfection of PKA (data not shown), as was in SK-N-BE(2)C cells. This cotransfection experiment was repeated in triplicate, resulting in the same pattern.

DBH-CAT construct in another DBH-negative cell line, the rat C6 glioma (Ishiguro et al., 1993; Table 2). Here, again, the CAT activity of the DBH-CAT construct increased only slightly, approximately twofold, even when cotransfected with the maximum amount of $\mathrm{PKA}_{\mathrm{c}}$.

\section{A protein kinase inhibitor (PKI) diminishes the forskolin-stimulated but not TPA-stimulated transcriptional activity of the DBH-CAT construct}

To assess the role of endogenous PKA in DBH gene regulation in greater detail, we tested the transcriptional activity of 2.6CAT following treatment with forskolin or phorbol ester, activators of PKA and protein kinase C, respectively. Treatment of SK$\mathrm{N}-\mathrm{BE}(2) \mathrm{C}$ cells with forskolin, but not with TPA, result in modest increase (approximately twofold) of intracellular activity of PKA (K.-S. Kim, unpublished observation). Treatment of cells with either forskolin (Fig. 3, top) or dibutyryl cAMP (data not shown) increased CAT activity approximately threefold. Phorbol ester (TPA) treatment enhanced CAT activity approximately fivefold. Furthermore, induction of CAT activity by forskolin and TPA was additive (Fig. 3, top).

We also examined the regulation of the transcriptional activity

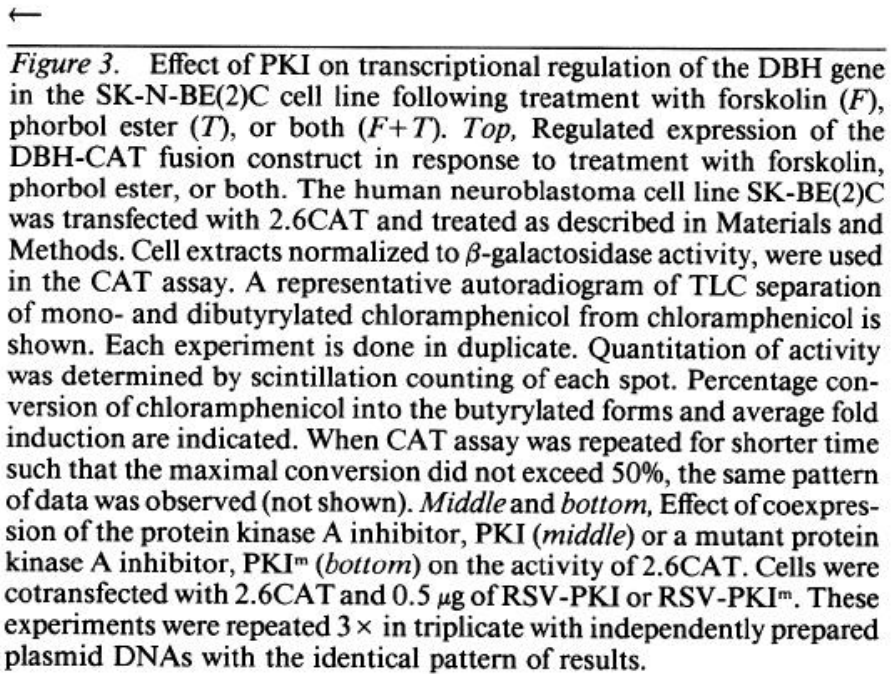

$\leftarrow$ phorbol ester $(T)$, or both $(F+T)$. Top, Regulated expression of the DBH-CAT fusion construct in response to treatment with forskolin, phorbol ester, or both. The human neuroblastoma cell line SK-BE(2)C was transfected with 2.6CAT and treated as described in Materials and Methods. Cell extracts normalized to $\beta$-galactosidase activity, were used in the CAT assay. A representative autoradiogram of TLC separation of mono- and dibutyrylated chloramphenicol from chloramphenicol is shown. Each experiment is done in duplicate. Quantitation of activity was determined by scintillation counting of each spot. Percentage conindur of chloramphenicol into the butyrylated forms and average fold such that the maximal conversion did not exceed $50 \%$, the same pattern of data was observed (not shown). Middle and bottom, Effect of coexpression of the protein kinase A inhibitor, PKI (middle) or a mutant protein kinase A inhibitor, $\mathrm{PKI}^{\mathrm{m}}$ (bottom) on the activity of 2.6CAT. Cells were experiments were repeated $3 \times$ in triplicate with independently prepared plasmid DNAs with the identical pattern of results. 


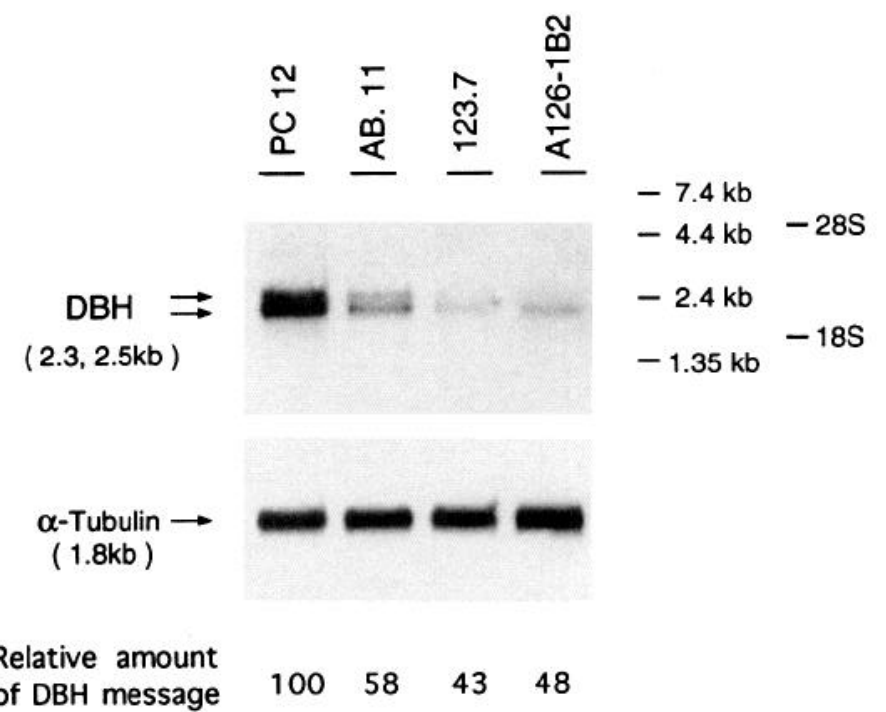

Figure 4. Basal steady-state DBH mRNA levels of three PKA-deficient PC12 cells. PolyA ${ }^{+}$RNA ( $\left.2 \mu \mathrm{g}\right)$ was loaded per each lane for Northern hybridization analysis. The $\mathrm{DBH}$ and $\alpha$-tubulin messages were detected consecutively using the same blot. Signals were quantitated and normalized as described in Materials and Methods. While the DBH mRNA was reduced by $40-60 \%$ compared to the wild type, signals for $\alpha$-tubulin was not altered at all. RNA size standards (Bethesda Research LabsGIBCO), $18 S$ and $28 S$ indicate that the sizes of the rat DBH mRNA are 2.3 and $2.5 \mathrm{~kb}$, slightly different from those previously reported (2.5 and $2.7 \mathrm{~kb}$; McMahon et al., 1992).

of $\triangle$ CRE 978CAT following treatment with forskolin or TPA. While the induction of CAT activity in response to forskolin treatment was severely diminished (Ishiguro et al., 1993), induction by TPA treatment was almost intact (four- to fivefold; data not shown), indicating that TPA induced transcription of the human DBH gene via the sequence motif(s) other than the CRE.

The signaling pathway specificities of forskolin and TPA were tested by coexpressing a peptide, PKI, that specifically inhibits PKA activity (Day et al., 1989). Enhancement of CAT activity of 2.6CAT by forskolin treatment was almost completely abolished by expression of PKI (Fig. 3, middle), indicating the direct involvement of PKA in this transcriptional induction pathway. PKI did not affect TPA-stimulated induction of CAT activity at all (Fig. 3, middle). Expression of $\mathrm{PKI}^{\mathrm{m}}$, an inactive mutant PKI peptide (Day et al., 1989), did not affect induction of CAT activity by either forskolin or TPA (Fig. 3, bottom). We obtained the same pattern when these experiments were performed in another DBH-expressing human neuroblastoma cell line, SKN-BE(2)M17 (data not shown).

When increasing amounts of RSV-PKI were cotransfected with 2.6CAT, basal CAT activity decreased only slightly (10$15 \%$; data not shown). Beyond $1 \mu \mathrm{g}$ of effector plasmid, both RSV-PKI and RSV-PKI ${ }^{\mathrm{m}}$ reduced CAT activity of the reporter constructs, indicating a nonspecific effect. This phenomenon has been reported previously, and may be due to competition for the limited amount of transcription factors ("squelching") (Ptashne, 1988).

Both basal and CAMP-inducible transcription of the DBH gene are reduced in all three PKA-deficient PC12 cell lines

To analyze the role of PKA in basal transcription of the DBH gene in a more direct manner, we measured DBH mRNA ex-

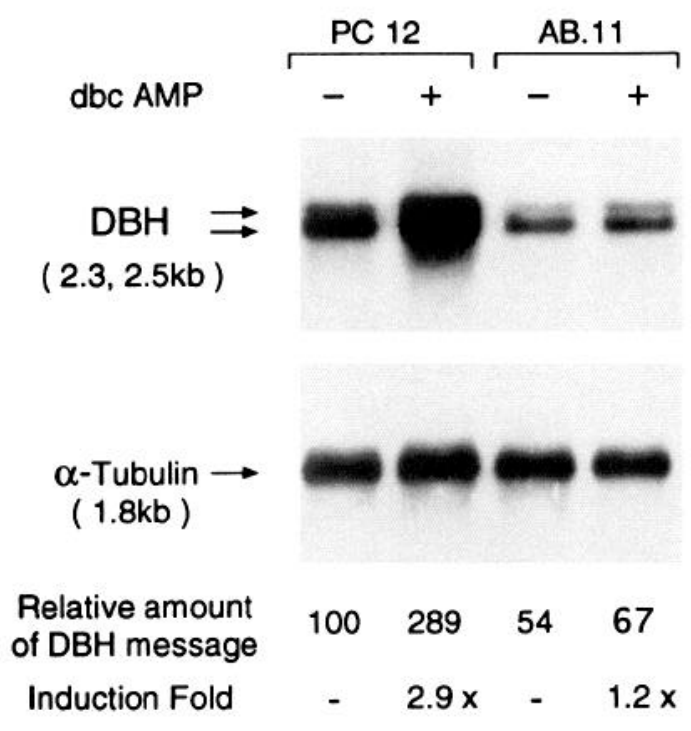

Figure 5. Northern blot analysis of rat DBH mRNA in response to activities of the cAMP-signaling pathway in normal and mutant $\mathrm{PC} 12$ cells. Twelve hours prior to harvest, cells were treated with dibutyryl cAMP ( $d b c A M P)$, or forskolin (data not shown). The mRNA of the rat DBH gene is upregulated in the parental $\mathrm{PC} 12$ cell line, but unaffected in a PKA-deficient line, $A B .11$. Two other PKA-deficient cell lines, 123.7 and A126-1B2, were similarly unaffected (data not shown).

pression in three PKA-deficient subclones of PC12. Two of these cell lines, AB.11 and 123.7 (Ginty et al., 1991a), had been rendered PKA deficient by the stable expression of mutant regulatory subunits of PKA, which cannot properly bind cAMP (Correll et al., 1989). Another cell line, A126-1B2, was isolated after $N$-methyl- $N^{\prime}$-nitro- $N$-nitrosoguanidine mutagenesis (Buskirk et al., 1985). All three cell lines express only $10-20 \%$ the PKA activity of wild-type PC12 cells, while levels of other kinases are not altered (Ginty et al., 1991a,b). Figure 4 shows that the basal level of both DBH transcripts was reduced by $40-60 \%$ in all three PKA-deficient cell lines as compared to that of the parental PC12 cell line. In contrast, the steady-state mRNA of the $\alpha$-tubulin gene was not altered in any of the mutant cell lines. In addition, our recent experiment demonstrated that mRNA level of the monoamine oxidase A, an enzyme that catalyzes the oxidative deamination of amines (Bach et al., 1988), is not altered in these mutant cell lines (K.-S. Kim, unpublished data). The role of PKA in transcriptional regulation of the DBH gene was further investigated by the addition of analogs of cAMP and forskolin to the mutant and wild-type PC12 cells. While extracellular dibutyryl cAMP and forskolin increased the steadystate mRNA levels of DBH approximately threefold in wildtype cells, it did not significantly increase DBH message in any of the mutant cell lines (Fig. 5, and data not shown), strongly supporting the conclusion that PKA mediates DBH gene induction by cAMP in $\mathrm{PC} 12$ cells.

\section{Discussion}

The cAMP-signaling pathway has an important functional impact on expression of catecholamine neurotransmitters by modulating their biosynthesis genes. cAMP can function either by direct activation of target molecules, as exemplified by channel proteins (Dhallan et al., 1990; Delgado et al., 1991), or indirectly by activating the effector molecule, cAMP-dependent protein kinase (Taylor et al., 1990). Several laboratories independently 
have assigned functional importance to the cAMP-signaling system in the regulation of the DBH gene (McMahon and Sabban, 1992; Shaskus et al., 1992; Ishiguro et al., 1993; Lamouroux et al., 1993); however, neither the molecular mechanisms nor the role of PKA has been defined. When increasing amounts of catalytic subunit of PKA were coexpressed with DBH-CAT constructs, we found that both CAT activity and correctly initiated transcripts increased in a dose-dependent manner, demonstrating that increased PKA activity can induce the transcriptional activity of the human $\mathrm{DBH}$ gene. Primer extension and sequencing analyses, using the same oligonucleotide as the primer, indicated that transcription is initiated at the $\mathrm{G}$ residue (Fig. 2; i.e., $\mathrm{C}$ residue in the sense strand) in the DBH-CAT construct, which had been originally mapped to position -1 of the endogenous gene (Kobayashi et al., 1989). This small discrepancy may have resulted from slight differences in the mobility of samples of sequencing reactions and primer extended mixtures.

Both the rat and human DBH genes contain several sequence motifs, in the $5^{\prime}$ upstream region, which can potentially respond to the cAMP-signaling pathway: the CRE, AP1, and AP2 sites (Cambi et al., 1989; Kobayashi et al., 1989). In the human DBH gene, deletion of a 14 bp region ( -189 to -176$)$, encompassing the CRE (TGACGTCC), which deviates from the consensus CRE motif (TGACGTCA) by a single base, drastically reduced basal promoter activity, and also significantly attenuated its responsiveness to treatment with forskolin (Ishiguro et al., 1993). Notably, this CRE-deleted DBH-CAT construct retained full responsiveness to treatment with $\mathrm{TPA}$, an activator of protein kinase $\mathrm{C}$, indicating that the CRE is not the target cis-regulatory site for transcriptional induction by PKC. To assess whether this CRE motif is the target of action of PKA in transcriptional regulation of the $\mathrm{DBH}$ gene, we showed that transcriptional stimulation in response to expression of $\mathrm{PKA}_{c}$ is dramatically reduced when the CRE is deleted (Table 1), strongly suggesting that PKA stimulates the transcriptional activity of the human DBH promoter through this CRE. These data, however, do not exclude the possibility that there are additional sequence motifs that can weakly respond to PKA. Interestingly, the rat gene contains a CRE motif (TGATGTCC) containing an additional difference from the consensus sequence, but the function of this CRE has not been studied (Shaskus et al., 1992; Ishiguro et al., 1993). Adjacent to this degenerate motif, the rat sequence contains a consensus AP1 motif(TGCGTCA). This sequence motif is also found in the cAMP-response element of the proenkephalin gene (Comb et al., 1986, 1988). Shaskus et al. (1992) reported that a DNA fragment including AP1, but not the complete CRE, can respond to transcriptional stimulation following treatment with cAMP or phorbol ester. Thus, the functionally important $c i s$-regulatory elements regulating the DBH gene may be different in the rat and human sequences.

The strong induction of $\mathrm{DBH}$ promoter activity by $\mathrm{PKA}_{c}$ appears to be cell specific. Even cotransfection of $1 \mu \mathrm{g}$ of $\mathrm{PKA}_{c}$, which exhibited the maximal induction in the SK-N-BE(2)C cell line, altered the transcriptional activity to a minimal degree in the HeLa and C6 glioma cell lines. Several genes, normally expressed in HeLa cells, have been demonstrated to be induced by increase of cAMP, indicating that this cell line has a functional cAMP-signaling pathway (Englander and Wilson, 1992; Thomas and Lublin, 1993). Indeed, it was clearly shown that treatment of the HeLa cells with forskolin efficiently upregulates the intracellular level of cAMP (Pauwels et al., 1993). In line with these reports, we observed that forskolin treatment in- creased the intracellular activity of PKA in HeLa cells (two- to threefold; K.-S. Kim et al., unpublished observation). Therefore, a lack of intact cAMP-signaling pathway is not a likely explanation for the unresponsiveness of the DBH-CAT construct to cotransfection with $\mathrm{PKA}_{\mathrm{c}}$ in these cell lines.

The reason for the inability of $\mathrm{PKA}_{c}$ to induce the $\mathrm{DBH}$ promoter activity in HeLa and C6 glioma cell lines is not known. Possible explanations include the following: (1) the CRE-binding protein(s), which activate $\mathrm{DBH}$ transcription, may be cell type-specific factor(s) (Habner, 1990); (2) the CRE-binding protein, possibly CREB (Montminy et al., 1990), may require additional protein factor(s) that is cell type specific; (3) the silencer region residing betwecn -490 and -263 bp (Ishiguro et al., 1993) may suppress $P_{K} A_{c}$-mediated induction of transcriptional activity in a cell-specific manner. Preliminary cotransfection analysis indicated that deletion of the silencer region partially restored the induction by PKA $_{c}$ (data not shown), suggesting an interaction between protein factors binding to the silencer region and proteins binding to the CRE.

Transient expression analyses showed that activation of PKA or PKC-induced transcription of the human DBH gene in an additive manner, suggesting that these pathways may work independently. Shaskus et al. (1992) reported that simultaneous treatment with cAMP and phorbol ester resulted in synergistic increases in rat $\mathrm{DBH}$ gene expression. It is possible that the discrepancy between these studies results from species-specific differences in $\mathrm{DBH}$ gene promoter structure. When a plasmid expressing a specific polypeptide inhibitor of PKA, RSV-PKI, was cotransfected with DBH-CAT constructs, the stimulatory effect of forskolin treatment was almost completely abolished. Thus, PKA is directly involved in forskolin-mediated transcriptional induction of the human DBH gene. Transcriptional induction in response to phorbol ester, however, does not require the intact activity of PKA, strongly suggesting that the signaling pathways activated by PKA and PKC are functionally independent in regulating $\mathrm{DBH}$ gene transcription.

Transient coexpression analysis indicated that transcriptional activity of the $\mathrm{DBH}$ promoter was diminished to a small but reproducible degree (10-15\%) by cotransfection with RSV-PKI. Since it would take considerable time for PKI to be transcribed, translated, and block intracellular PKA activity, the CAT activities expressed during that interim may mask, in part, the real effect of PKI on basal expression of the reporter construct. This possibility prompted us to analyze several PKA-deficient PC12 cell lines (Buskirk ct al., 1985; Ginty ct al., 1991a,b). In all three mutant cell lines characterized in this study, the uninduced steady-state mRNA levels were diminished by approximately $50 \%$ of the wild-type PC12 cell line. These data strongly suggest that PKA plays an important role for uninduced, basal transcription of the $\mathrm{DBH}$ gene. Previous studies indicated that blockade of intracellular PKA activity results in deeper decrement in basal transcription of the TH gene when examined either in PKA-deficient PC12 cells (K.-S. Kim et al., $1993 b)$ or in cotransfection analysis using SK-N-BE(2)C cell line (K.-S. Kim et al., 1994). When extracellular cAMP was added to PC1 2 cells, steady-state mRNA levels of the DBH gene were increased by threefold. In contrast, this effect was almost abolished in all three PKA-deficient cell lines. The same treatment in wild-type PC1 2 cells induced the mRNA level of the TH gene only modestly (1.8-fold), and this induction also disappeared in mutant cell lines (K.-S. Kim et al., 1993b). Thus, these data imply that the PKA pathway may be quantitatively 
less essential in the regulation of basal transcription of the $\mathrm{DBH}$ gene as compared with the TH gene. However, stimulation of PKA activity can induce the DBH gene in response to extracellular cAMP more efficiently. In vivo, these two parameters, that is, basal versus cAMP-inducible transcription, could interact to define the relative influence of PKA in TH and DBH gene regulation.

Since the early work by Levitt et al. (1965), tyrosine hydroxylase has been thought to be the rate-limiting enzyme in catecholamine biosynthesis. More recently, however, accumulating evidence has indicated that both $\mathrm{TH}$ and $\mathrm{DBH}$ genes are subject to coregulation in response to different stimuli (Otten and Thoenen, 1976; Sabban et al., 1983; Acheson et al., 1984; Faucon Biguet et al., 1986; Lewis et al., 1987; Badoyannis et al., 1991; McMahon et al., 1992; K. T. Kim et al., 1993; Lamouroux et al., 1993; Wessel and Joh, 1993). This study, for the first time, directly demonstrates an important role of PKA in transcriptional regulation of the $\mathrm{DBH}$ gene in noradrenergic cells, and suggests that PKA may coregulate transcription of the $\mathrm{TH}$ and DBH genes in response to extracellular stimuli that are linked to cAMP-signaling pathway. In conclusion, the results in this report, together with those from previous studies (Ishiguro et al., 1993; K.-S. Kim et al., 1993a,b, 1994), suggest that the cAMP-signaling pathway, via PKA, can modulate catecholamine expression by regulating transcription of both $\mathrm{DBH}$ and TH. This suggests that the levels of these enzymes are actively regulated by cAMP-dependent processes in vivo and raises the question of whether both $\mathrm{TH}$ and DBH play important regulatory roles in controlling the availability of catecholamines in the nervous system.

\section{References}

Acheson AL, Naujoks K, Thoenen H (1984) Nerve growth factormediated enzyme induction in primary cultures of bovine adrenal chromaffin cells: specificity and level of regulation. J Neurosci 4:17711780

Bach AWJ, Lan NC, Johnson DL, Abell CW, Bembenek ME, Kwan S-W, Seeberg PH, Shih JC (1988) cDNA cloning of human monoamine oxidase $A$ and $B$ : molecular basis of differences in enzymatic properties. Proc Natl Acad Sci USA 85:4934-4938.

Badley JE, Bishop GA, St. John T, Frelinger JA (1988) A simple, rapid method for the purification of poly $A^{+}$RNA. Biotech 6:114-116.

Badoyannis HC, Sharma, SC, Sabban EL (1991) The differential effects of cell density and NGF on the expression of tyrosine hydroxylase and dopamine $\beta$-hydroxylase in PC12 cells. Mol Brain Res 11:79_ 87.

Buskirk RV, Corcoran T, Wagner J (1985) Clonal variants of PC12 pheochromocytoma cells with defects in CAMP-dependent protein kinases induce ornithine decarboxylase in response to nerve growth factor but not to adenosine agonists. Mol Cell Biol 5:1984-1992.

Cambi F, Fung B, Chikaraishi D (1989) 5' flanking DNA sequences direct cell-specific expression of rat tyrosine hydroxylase. $J$ Neurochem 53:1656-1659.

Carroll JM, Kim KS, Kim KT, Goodman HM, Joh TH (1991) Effects of second messenger system activation on functional expression of tyrosine hydroxylase fusion gene constructs in neuronal and nonneuronal cells. J Mol Neurosci 3:65-74.

Ciccarone V, Spengler BA, Meyers MB, Biedler JL, Ross RA (1989) Phenotypic diversification in human neuroblastoma cells: expression of distinct neural crest lineages. Cancer Res 49:219-225.

Comb M, Birnberg NC, Seasholtz A, Herbert E, Goodman H (1986) A cyclic AMP- and phorbol ester-inducible DNA element. Nature 323:353-356.

Comb M, Mermod N, Hyman SE, Pearlberg J, Ross ME, Goodman HM (1988) Proteins bound at adjacent DNA elements act synergistically to regulate human proenkephalin cAMP inducible transcription. EMBO J 7:3793-3805.

Correll LA, Woodford TA, Corbin JD, Mellon PL, McKnight GS (1989)
Functional characterization of cAMP-binding mutations in type I protein kinase. J Biol Chem 264:16672-16678.

Day RN, Walder J, Maurer RA (1989) A protein kinase inhibitor gene reduces both basal and multihormone-stimulated prolactin gene transcription. J Biol Chem 264:431-436.

Delgado R, Hidalgo P, Diaz F, Latorre R, Labarca P (1991) A cyclic AMP-activated $\mathrm{K}^{+}$channel in Drosophila larval muscle is persistently activated in dunce. Proc Natl Acad Sci USA 88:557-569.

Dhallan RS, Yau KW, Schrader KA, Reed RR (1990) Primary structure and functional expression of a cyclic nucleotide-activated channel from olfactory neurons. Nature 347:184-187.

Englander EW, Wilson SH (1992) The cloned promoter of the human DNA beta-polymerase gene contains a AMP response element functional in HeLa cells. DNA Cell Biol 11:61-69.

Faucon Biguet N, Buda M, Lamouroux A, Samolyk D, Mallet J (1986) Time course of the changes of TH mRNA in rat brain and adrenal medulla after a single injection of reserpine. EMBO J 2:287-291.

Friedman S, Kaufman S (1965) 3,4-Dihydroxyphenylethylamine $\beta$-hydroxylase. J Biol Chem 240:4763-4773.

Ginty DD, Glowacka D, DeFranco C, Wagner J (1991a) Nerve growth factor-induced neuronal differentiation after dominant repression of both type I and II cAMP-dependent protein kinase activity. J Biol Chem 266:15325-15333.

Ginty DD, Glowacka D, Bader DS, Hidaka H, Wagner J (199lb) Induction of immediate early genes by $\mathrm{Ca}^{2+}$ influx requires cAMPdependent protein kinase in PC12 cells. J Biol Chem 266:17454 17458.

Habener JH (1990) Cyclic AMP response element binding proteins: a cornucopia of transcription factors. Mol Endocrinol 4:1087-1094.

Ishiguro H, Kim KT, Joh TH, Kim KS (1993) Neuron-specific expression of the human dopamine $\beta$-hydroxylase gene requires both cAMP response element and a silencer region. J Biol Chem 268: 17987-17994.

Kim KS, Lee MG, Carroll J, Joh TH (1993a) Both the basal and inducible transcription of the tyrosine hydroxylase gene are dependent upon a cAMP response element. J Biol Chem 268:15689-15695.

Kim KS, Park DH, Wessel TC, Song B, Wagner J, Joh TH (1993b) A dual role for the cAMP-dependent protein kinase on tyrosine hydroxylase gene expression. Proc Natl Acad Sci USA 90:3471-3475.

Kim KS, Tinti C, Song B, Cubells JF, Joh TH (1994) cAMP-dependent protein kinase regulates basal and cAMP-stimulated, but not phorbol ester-stimulated transcription of the tyrosine hydroxylase gene. J Neurochem, in press.

Kim KT, Park DH, Joh TH (1993) Parallel upregulation of catecholamine biosynthetic enzymes by dexamethasone in PC12 cells. J Neurochem 60:946-951.

Kirshner N, Goodall McC (1957) Separation of adrenaline, noradrenaline, and hydroxytyramine by ion exchange chromatography. J Biol Chem 226:207-212.

Kobayashi K, Kurasawa Y, Fujita K, Nagatsu T (1989) Human dopamine $\beta$-hydroxylase gene: two mRNA types having different 3'terminal regions are produced through alternative polyadenylation. Nucleic Acids Res 17:1089-1102.

Lamouroux A, Houhou L, Faucon Biguet N, Serck-Hanssen G, Guibert B, Icard-Liepkalns C, Mallet J (1993) Analysis of the human dopamine $\beta$-hydroxylase promoter: transcriptional induction by cyclic AMP. J Neurochem 60:364-367.

Lee CQ, Yun Y, Hoeffler JP, Habener JF (1990) Cyclic-AMP-responsive transcriptional activation of CREB-327 involves interdependent phosphorylated subdomains. EMBO J 9:4455-4465.

Levitt M, Spector S, Sjoerdsma A, Udenfriend S (1965) Elucidation of the rate-limiting step in norepinephrine biosynthesis in the perfused guinea-pig heart. J Pharmacol Exp Ther 148:1-7.

Lewis EJ, Harrington CA, Chikaraishi DM (1987) Transcriptional regulation of the tyrosine hydroxylase gene by glucocorticoid and cyclic AMP. Proc Natl Acad Sci USA 84:3550-3554.

McKnight SL, Kingsbury R (1982) Transcriptional control signals of a eukaryotic protein-coding gene. Science 217:316-324.

McMahon A, Saban EL (1992) Regulation of expression of dopamine $\beta$-hydroxylase in PC12 cells by glucocorticoids and cyclic AMP analogues. J Neurochem 59:2040-2047.

McMahon A, Kvetnansky R, Fukuhara K, Weise VK, Kopin IJ, Sabban EL (1992) Regulation of tyrosine hydroxylase and dopamine $\beta$-hydroxylase mRNA levels in rat adrenals by a single and rcpcated immobilization stress. J Neurochem 58:2124-2130. 
Montminy MR, Gonzalez GA, Yamamoto KK (1990) Regulation of cAMP-inducible genes by CREB. Trends Neurosci 13:184-188.

Otten U, Thoenen H (1976) Selective induction of tyrosine hydroxylase and dopamine $\beta$-hydroxylase in sympathetic ganglia in organ culture: role of glucocorticoids as modulators. Mol Pharmacol 12: 353-361.

Pauwels PJ, Van Gompel P, Leysen JE (1993) Activity of serotonin (5-HT) receptor agonists, partial agonists and antagonists at cloned human 5-HT1A receptors that are negatively coupled to adenylate cyclase in permanently transfected HeLa cells. Biochem J 45:375383.

Ptashne M (1988) How eukaryotic transcription activators work. Nature 335:683-689.

Roskoski R (1983) Assay of protein kinase. Methods Enzymol 99: 3-6.

Sabban EL, Goldstein M, Greene LA (1983) Regulation of the multiple forms of dopamine $\beta$-hydroxylase by nerve growth factor, dexameth- asone, and dibutyryl cyclic AMP in the $\mathrm{PC} 12$ pheochromocytoma cell line. J Biol Chem 258:7819-7823.

Shaskus J, Greco D, Asnani LP, Lewis EJ (1992) A bifunctional genetic regulatory element of the rat dopamine $\beta$-hydroxylase gene influences cell type specificity and second messenger-mediated transcription. J Biol Chem 267:18821-18830.

Taylor SS, Buechler I, Yonemoto W (1990) cAMP-dependent protein kinase: framework for a diverse family of regulatory enzymes. Annu Rev Biochem 59:971-1005.

Thomas DJ, Lublin DM (1993) Identification of 5'-flanking regions affection the expression of the human decay accelerating factor gene and their role in tissue-specific expression. J Immunol 150:151-160.

Wessel TC, Joh TH (1993) Parallel upregulation of catecholaminesynthesizing enzymes in rat brain and adrenal gland: effects of reserpine and correlation with immediate early gene expression. Mol Brain Res 15:349-360. 